\title{
La adopción de medidas coercitivas por los organismos regionales: un análisis del artículo 53 de la Carta de las Naciones Unidas a la luz de la práctica de la OEA*
}

\section{The Adoption of Enforcement Measures by Regional Agencies: an Analysis of Article 53 of the Charter of the United Nations in the Light of the Practice of the $O A S$}

\section{Luciano Pezzano**}

Sumario: I. Introducción. II. El artículo 53 de la Carta de las Naciones Unidas. III. Las medidas adoptadas por la OEA y la práctica del Consejo de Seguridad. IV. Consideraciones finales. V. Bibliografía.

* Artículo recibido el 14 de julio de 2011 y aprobado para publicación el 28 de septiembre de 2011.

** Abogado (UCES San Francisco, Córdoba, Argentina, 2007); maestrando en Relaciones Internacionales (CEA-UNC, Córdoba, Argentina); jefe de Trabajos Prácticos de la cátedra de Derecho Internacional Público y de la Integración (UCES San Francisco, Córdoba, Argentina). 
RESUMEN: El artículo analiza la interpretación del artículo 53 de la Carta de las Naciones Unidas por parte del Consejo de Seguridad en relación con la aplicación de medidas coercitivas por los organismos regionales a través de la práctica de la Organización de los Estados Americanos.

Palabras clave: medidas coercitivas, Consejo de Seguridad, organismos regionales, artículo 53 de la Carta de las Naciones Unidas.

ABSTRACT: The article analyzes the interpretation of article 53 of the Charter of the United Nations by the Security Council with regard to the implementation of enforcement measures by the regional agencies, through the practice of the Organization of American States.

Descriptors: enforcement measures, Security Council, regional agencies, article 53 of the Charter of the United Nations.

RÉSUMÉ: L'article analyse l'interprétation de l'article 53 de la Charte des Nations Unies par le Conseil de Sécurité par rapport à l'application de mesures coercitives par les organismes régionaux, à travers la pratique de l'Organisation des États Américains.

Mots-Clés: mesures coercitives, Conseil de Sécurité, organismes régionaux, article 53 de la Charte des Nations Unies. 


\section{INTRODUCCIÓN}

El Capítulo VIII de la Carta de las Naciones Unidas se refiere a los acuerdos u organismos regionales "cuyo fin sea entender en los asuntos relativos al mantenimiento de la paz y seguridad internacionales y susceptibles de acción regional" (artículo 52.1). Por su parte, el artículo 1 de la Carta de la Organización de los Estados Americanos (OEA), expresamente reconoce: "Dentro de las Naciones Unidas, la Organización de los Estados Americanos constituye un organismo regional”, y entre sus propósitos esenciales, el artículo 2, inciso a) incluye: "Afianzar la paz y la seguridad del Continente". No cabe duda, entonces, de la caracterización de la OEA como uno de los “organismos regionales" a los que hace referencia el Capítulo VIII de la Carta de la ONU.

Pero, ¿qué medidas pueden tomar los organismos regionales, en este caso la OEA, para mantener la paz y la seguridad internacionales? ¿Cómo juegan al respecto las disposiciones de la Carta de las Naciones Unidas, en particular el artículo 53? ¿Qué dificultades interpretativas arroja la citada norma? ¿Qué medidas tomó la OEA que se puedan considerar dentro de los límites de ese artículo? ¿De qué manera ha sido interpretado el artículo 53 en el Consejo de Seguridad en relación con las medidas tomadas por la OEA?

El propósito de este artículo es, entonces, estudiar, dentro del marco del Capítulo VIII de la Carta de las Naciones Unidas, y en especial de su artículo 53, la adopción de medidas coercitivas por los organismos regionales, en particular, la OEA. Es oportuno aclarar que el análisis se circunscribirá al ámbito estrictamente jurídico de la cuestión, sin entrar al estudio de aspectos políticos que, si bien podrían enriquecer el tema, exceden los límites del presente trabajo.

\section{El ARTÍ́CULO 53 DE LA CARTA DE LAS NACIONES UNIDAS}

El párrafo 1 del artículo 53 de la Carta establece: "El Consejo de Seguridad utilizará dichos acuerdos u organismos regionales, si a ello 
hubiere lugar, para aplicar medidas coercitivas bajo su autoridad. Sin embargo, no se aplicarán medidas coercitivas en virtud de acuerdos regionales o por organismos regionales sin autorización del Consejo de Seguridad...”.

El artículo plantea dos supuestos bien diferenciados: por un lado, el Consejo de Seguridad puede utilizar a los acuerdos u organismos regionales para aplicar medidas coercitivas, "bajo su autoridad". Por el otro, es claro al establecer que los organismos regionales no pueden por sí mismos aplicar "medidas coercitivas", requiriendo para ello la autorización del Consejo. El quid de la cuestión radica en determinar qué son las "medidas coercitivas", ya que la Carta no las define en ninguna de sus disposiciones, pese a que hace referencia a ellas en los artículos 2.5, $2.7,5,45,50$ y 53, en varios de ellos junto a las "medidas preventivas". Para nosotros resulta evidente que estas medidas, preventivas y coercitivas, son las "medidas colectivas eficaces" a las que hace referencia el artículo 1.1, que son tomadas "para prevenir y eliminar amenazas a la paz, y para suprimir actos de agresión u otros quebrantamientos de la paz". Estas medidas no pueden ser otras que las establecidas en el Capítulo VII, "Acción en caso de amenazas a la paz, quebrantamientos de la paz o actos de agresión”, específicamente, y de conformidad con lo establecido por el artículo 39, las contempladas en los artículos $41^{1}$ y $42 .^{2}$ La diferencia esencial de las dos clases de medidas radica en que las del artículo 41 no implican el uso de la fuerza armada, y las del artículo 42 sí lo implican. Ahora bien, ¿ambos tipos de medidas son "medidas coercitivas" o sólo lo

1 "El Consejo de Seguridad podrá decidir qué medidas que no impliquen el uso de la fuerza armada han de emplearse para hacer efectivas sus decisiones, y podrá instar a los Miembros de las Naciones Unidas a que apliquen dichas medidas, que podrán comprender la interrupción total o parcial de las relaciones económicas y de las comunicaciones ferroviarias, marítimas, aéreas, postales, telegráficas, radioeléctricas, y otros medios de comunicación, así como la ruptura de relaciones diplomáticas”.

2 "Si el Consejo de Seguridad estimare que las medidas de que trata el Artículo 41 pueden ser inadecuadas o han demostrado serlo, podrá ejercer, por medio de fuerzas aéreas, navales o terrestres, la acción que sea necesaria para mantener o restablecer la paz y la seguridad internacionales. Tal acción podrá comprender demostraciones, bloqueos y otras operaciones ejecutadas por fuerzas aéreas, navales o terrestres de Miembros de las Naciones Unidas”. 
son las que implican el uso de la fuerza armada? El artículo $45^{3}$ parece dar una pauta de interpretación al referirse exclusivamente a "acción coercitiva”, y es indudable que se trata de la acción del artículo 42. Es decir, parecería circunscribir el concepto de "medidas coercitivas" a las que implican el uso de la fuerza armada.

Pese a ello, la doctrina está dividida en cuanto al alcance de la noción de “medidas coercitivas" en el artículo 53. Así, Delpech afirma:

El texto contiene el principio sostenido por los Estados Unidos y algunos países occidentales - desde los trabajos preparatorios de Dumbarton Oaks-, en el sentido de que "las medidas coercitivas" - "enforcement action", dice el texto original inglés - sólo pueden ser aplicadas en el ámbito de "acuerdos u organismos regionales", con la autorización y bajo la autoridad del Consejo de Seguridad. En rigor, como bien señalan Goodrich, Hambro y Simons, los términos enforcement action "was intended to mean any and all measures the Security Council was authorized to take under Articles 41 and $42 .^{4}$

Por su parte, Cardona Llorens, después de modificar su postura anterior, ${ }^{5}$ sostiene:

[L]os acuerdos u organismos regionales no tienen prohibida la adopción de cualquier medida de presión contra un Estado para obligarle a cumplir con sus obligaciones o restablecer la paz y la seguridad internacionales. Tanto en el marco de la responsabilidad internacional como en el marco más amplio de las competencias

3 "A fin de que la Organización pueda tomar medidas militares urgentes, sus Miembros mantendrán contingentes de fuerzas aéreas nacionales inmediatamente disponibles para la ejecución combinada de una acción coercitiva internacional. La potencia y el grado de preparación de estos contingentes y los planes para su acción combinada serán determinados, dentro de los límites establecidos en el convenio o convenios especiales de que trata el Artículo 43, por el Consejo de Seguridad con la ayuda del Comité de Estado Mayor" (cursivas añadidas).

4 Delpech, Marcelo, Carta de las Naciones Unidas anotada, Buenos Aires, Zavalía, 2005, p. 82.

En la que consideraba a las medidas que no implican el uso de la fuerza dentro de las "medidas coercitivas". Cardona Llorens, Jorge, "El mantenimiento de la paz y la seguridad internacionales", en Diez de Velasco Vallejo, Manuel, Las Organizaciones Internacionales, 10 a. ed., Madrid, Tecnos, 1997, p. 235. Volveremos sobre ello más adelante. 
atribuidas por los Estados miembros del acuerdo regional para que pueda adoptar medidas contra ellos mismos si se dan determinadas circunstancias, los acuerdos regionales pueden adoptar tanto contramedidas legítimas como medidas de presión contra un Estado miembro... [N]o se puede considerar que lo que está permitido a los Estados individualmente les está prohibido a los Estados colectivamente. Así pues, los acuerdos regionales pueden adoptar medidas de presión con los mismos requisitos y los mismos límites que los Estados en su actuación individual: a) cumplir los requisitos de legitimación activa, ya sea porque están legitimados para adoptar medidas en el marco de las relaciones de responsabilidad internacional, ya sea porque los mismos Estados destinatarios de las mismas le han atribuido previamente la competencia para adoptar ese tipo de medidas para el caso de que se diera ese supuesto concreto; y b) no violar, en ningún caso, los principios de no intervención en los asuntos internos y de prohibición del uso de la fuerza armada... Situación distinta es si las medidas que pretende adoptar el acuerdo u organismo regional violan los principios de no intervención en los asuntos internos o de prohibición del uso de la fuerza... [E]l único órgano que puede adoptar medidas coercitivas sin que le sean aplicables estos principios es el Consejo de Seguridad. Y es a este tipo de medidas a las que, conforme a la interpretación dada por la práctica de la Organización, hace referencia el límite del Artículo 53 de la Carta. ${ }^{6}$

En la misma línea, y partiendo de la premisa de que el único tipo de fuerza que les está prohibido a los Estados —individualmente o a través de organismos regionales — según el artículo 2.4 de la Carta es la fuerza armada, Villani concluye:

[S]i el propósito de la autorización del Consejo de Seguridad en virtud del artículo 53 párrafo 1, segunda frase, es permitir una acción coercitiva por parte una organización regional, que sería ilegal en ausencia de dicha autorización, entonces la autorización solo es necesaria para medidas que implican el uso o la amenaza

6 Cardona Llorens, Jorge, "El mantenimiento de la paz y la seguridad internacionales”, en Diez De Velasco Vallejo, Manuel, Las Organizaciones Internacionales, 13a. ed., Madrid, Tecnos, 2003, pp. 254 y 255. En el mismo sentido, aunque algo dubitativo, véase Berenson, William M., La estructura de la Organización de los Estados Americanos: una reseña, http: / /www.oas.org/ legal/spanish / WMB\%20CARTA\%20DE\%LA\%200EA\%20REV\%2029\%20de\%20enero\%20 de\%202002.doc. 
de la fuerza armada, porque la medidas de naturaleza diferente no son ilegales en virtud de la Carta. ${ }^{7}$

Estas disímiles interpretaciones hacen necesario estudiar cómo ha sido aplicada la norma, y dado que el propósito de este artículo es analizar las medidas tomadas por la OEA, veremos a continuación la práctica del Consejo de Seguridad en relación con las medidas adoptadas en el sistema interamericano.

\section{LAS MEDIDAS ADOPTADAS POR LA OEA \\ Y LA PRÁCTICA DEL CONSEJO DE SEGURIDAD}

\section{Fundamento jurídico de las medidas adoptadas por la OEA}

La Carta de la OEA establece en su Capítulo VI las normas sobre seguridad colectiva. En particular, el artículo 29 dispone:

Si la inviolabilidad o la integridad del territorio o la soberanía o la independencia política de cualquier Estado americano fueren afectadas por un ataque armado o por una agresión que no sea ataque armado, o por un conflicto extracontinental o por un conflicto entre dos o más Estados americanos o por cualquier otro hecho o situación que pueda poner en peligro la paz de América, los Estados americanos en desarrollo de los principios de la solidaridad continental o de la legítima defensa colectiva, aplicarán las medidas y procedimientos establecidos en los tratados especiales, existentes en la materia.

De conformidad a lo establecido en la Carta, tales medidas están contempladas en el Tratado Interamericano de Asistencia Recíproca (TIAR) _el único de los "tratados especiales" existente en la materia_-, cuyo artículo 8 dispone:

7 Villani, Ugo, “The Security Council's Authorization of Enforcement Action by Regional Organizations", en Frowein, L. A. y Wolfrum, R. (eds.), Max Planck Yearbook of United Nations Law, Kluwer Law International, 2002, vol. 6, p. 539. 
Para los efectos de este Tratado, las medidas que el Órgano de Consulta acuerde comprenderán una o más de las siguientes: el retiro de los jefes de misión; la ruptura de las relaciones diplomáticas; la ruptura de las relaciones consulares; la interrupción parcial o total de las relaciones económicas, o de las comunicaciones ferroviarias, marítimas, aéreas, postales, telegráficas, telefónicas, radiotelefónicas o radiotelegráficas, y el empleo de la fuerza armada. ${ }^{8}$

En virtud de los artículos 11 del TIAR y 61 de la Carta, la Reunión de Consulta de Ministros de Relaciones Exteriores es el Órgano de Consulta (el Consejo Permanente de la Organización puede actuar como Órgano de Consulta según el artículo 83 de la Carta). En cuanto al presupuesto para su convocatoria, según el citado artículo 29, es la afectación de la inviolabilidad o la integridad del territorio o la soberanía o la independencia política de cualquier Estado americano por: un ataque armado o agresión que no sea ataque armado (artículos 3o. y 9o. TIAR); un conflicto extracontinental (artículo 6o., TIAR); un conflicto entre dos o más Estados americanos (artículo 7o., TIAR); cualquier hecho o situación que pueda poner en peligro la paz en América (artículo 6o., TIAR).

De los cinco casos que analizaremos a continuación, los primeros cuatro hallan su fundamento en las disposiciones citadas de la Carta de la OEA y/o el TIAR, mientras que el quinto tiene una base jurídica diferente que analizaremos más adelante. Debemos señalar, no obstante, que la naturaleza de los casos es diferente. Así, en el primero, se trató de un conflicto entre dos Estados americanos (República Dominicana y Venezuela); en el caso de Cuba se denunció que la intervención de potencias extracontinentales ponía en peligro la paz y la seguridad de todo el continente; relacionado al anterior, la Crisis de los Misiles fue un conflicto entre un Estado americano y una potencia extracontinental en territorio americano; los dos casos restantes comenzaron como conflictos internos, pero cada uno adquirió luego ribetes particulares (particularmente en lo que respecta al consentimiento dado por cada gobierno a las medidas implementadas por la OEA).

8 A diferencia del resto de las medidas, el uso de la fuerza armada está limitado a los casos de legítima defensa colectiva. Cada vez que nos refiramos al artículo 8 del TIAR lo haremos con esta salvedad. 


\section{A. El caso de la República Dominicana en la Sexta Reunión de Consulta}

\section{a. La cuestión en la Sexta Reunión de Consulta}

En julio de 1960, y a raíz de ciertos actos de la República Dominicana (el denominado "régimen de Trujillo") contra Venezuela, el gobierno de este país solicitó la convocatoria a la Reunión de Consulta de Ministros de Relaciones Exteriores, en la que se aprobó la resolución I, y se resolvió “condenar enérgicamente la participación del Gobierno de la República Dominicana en los actos de agresión e intervención contra el Estado de Venezuela que culminaron en el atentado contra la vida del Presidente de dicho país”, y por la que,

de conformidad con lo dispuesto en los Artículos 6o. y 8o. del Tratado Interamericano de Asistencia Recíproca, acordó aplicar las siguientes medidas: a) Ruptura de relaciones diplomáticas de todos los Estados Miembros con la República Dominicana; b) Interrupción parcial de relaciones económicas de todos los Estados Miembros con la República Dominicana, comenzando por la suspensión inmediata del comercio de armas e implementos de guerra de toda clase. El Consejo de la Organización de los Estados Americanos estudiará, según las circunstancias y con la debida consideración de las limitaciones constitucionales o legales de todos y cada uno de los Estados Miembros, la posibilidad y conveniencia de extender la suspensión del comercio con la República Dominicana a otros artículos. ${ }^{9}$

b. Debates en el Consejo de Seguridad

Por carta de 5 de septiembre de 1960, la URSS pidió, en virtud del artículo 53 de la Carta, una reunión urgente del Consejo de Seguridad para examinar la decisión adoptada por la OEA con respecto a la República Dominicana y aprobar esa decisión. En la 893a. sesión, el

9 OEA, Acta Final de la Sexta Reunión de Consulta de Ministros de Relaciones Exteriores, San José, Costa Rica, 16.21 de agosto de 1960. 
representante de la URSS presentó un proyecto de resolución en virtud del cual el Consejo, "Teniendo presente el Artículo 53 de la Carta de las Naciones Unidas”, hubiese aprobado la resolución de la Sexta Reunión de Consulta. En la misma sesión, los representantes de la Argentina, el Ecuador y los Estados Unidos presentaron conjuntamente un proyecto de resolución en virtud del cual el Consejo, habiendo recibido el informe remitido por el secretario general de la OEA en que se transmitía el Acta Final de la Sexta Reunión de Consulta, tomaba nota de dicho informe "y especialmente de la resolución I aprobada en dicha Reunión por la que se acordó la aplicación de medidas respecto de la República Dominicana”. El representante de la URSS dijo que la decisión adoptada por la OEA constituía una medida coercitiva en el sentido del artículo 53. De conformidad con ese artículo, el Consejo era el único órgano competente para autorizar la aplicación de medidas coercitivas por parte de los organismos regionales y toda medida coercitiva adoptada sin su autorización por un organismo regional sería contraria a la Carta; las medidas aplicadas contra la República Dominicana se encontraban entre las que no implicaban el uso de la fuerza y eran medidas coercitivas porque el Consejo podía utilizarlas para obligar a un agresor a poner fin a los actos de agresión contra otro Estado y para impedir que se repitiera la agresión. Dado que la finalidad de las medidas adoptadas contra la República Dominicana era obligar a su gobierno a desistir de realizar actos que constituían una amenaza a la paz y a la seguridad, no podía aducirse que no se trataba de medidas coercitivas. Por lo tanto, con arreglo a lo dispuesto en el artículo 53, el Consejo tenía el deber de aprobar las decisiones de la OEA y de tomar, por sí mismo, las decisiones apropiadas. Esa aprobación no sólo daría fuerza jurídica a las decisiones del organismo regional destinadas a salvaguardar la paz y la seguridad internacionales, sino que también las haría más eficaces, ya que en tal caso contarían con el apoyo de todas las Naciones Unidas.

Un representante que apoyó el proyecto de la URSS señaló que la cuestión de la relación entre los acuerdos regionales y el Consejo de Seguridad en lo relativo al mantenimiento de la paz y la seguridad internacionales estaba definida en el Capítulo VIII de la Carta, y especialmente en el artículo 53. No podía compartir la opinión de que la expresión "medidas coercitivas" se refiriera sólo al uso de la fuerza militar. 
El derecho a emplear fuerzas armadas en acciones concernientes a una amenaza a la paz se atribuía exclusivamente al Consejo de Seguridad en virtud del Capítulo VII de la Carta. No existía otra disposición que confiriera ese derecho a ningún acuerdo u organización regional. Por consiguiente, si había que excluir del ámbito de aplicación del artículo 53 el caso del empleo de la fuerza, ello significaba que los redactores de dicho artículo habían tenido presentes sólo aquellas medidas o sanciones distintas de la acción militar. El Consejo, según lo dispuesto en el artículo 41, o los acuerdos regionales, según lo dispuesto en el artículo 53, podían decidir la aplicación de sanciones o medidas coercitivas de carácter económico o político. Pero en el caso de los acuerdos regionales, las medidas coercitivas debían ser autorizadas por el Consejo de Seguridad.

El representante de la Argentina hizo notar que era la primera vez que se planteaba en el Consejo la cuestión de la interpretación del artículo 53 en relación con medidas adoptadas por un organismo regional. Advirtiendo que los partidarios del proyecto de resolución de la URSS opinaban que el Consejo era competente, en virtud del artículo 53, para aprobar las medidas adoptadas por la OEA, sostuvo que, a contrario sensu, esa opinión implicaba también que el Consejo estaba facultado para anular o revisar tales medidas. Expresó que existían argumentos poderosos que abonaban la tesis según la cual las medidas tomadas en el ámbito regional sólo estarían sujetas a ratificación del Consejo si implicaban el uso de la fuerza armada. Los organismos regionales debían estar facultados para resolver los problemas que no trascendieran los límites de la región correspondiente. El representante de los Estados Unidos consideró significativo que ningún miembro de la OEA hubiera recabado la autorización del Consejo con arreglo a dicho artículo para adoptar medidas en relación con esas decisiones. Según el representante del Ecuador, podía plantearse la cuestión de si la autorización del Consejo era necesaria solamente para aquellas medidas que, como el uso de la fuerza, violarían el derecho internacional si se tomaran sin la aprobación del Consejo, pero no para aquellas medidas que, como la ruptura de relaciones diplomáticas, constituían un derecho privativo de todo Estado soberano. En vista de esas interrogantes, dicho representante opinó que el artículo 53 no debía utilizarse para subordinar rígidamente 
la acción de un organismo regional a la autorización del Consejo de Seguridad, menoscabando así la capacidad de esos organismos para tomar medidas prontas y eficaces para el mantenimiento de la paz y la seguridad internacionales en el contexto de las circunstancias de la región.

Los representantes que apoyaban el proyecto de resolución de las tres potencias estimaron que la autorización del Consejo sólo se requería cuando se trataba de decisiones de organismos regionales cuya ejecución implicaba el uso de la fuerza, lo que no ocurría en el caso. Se observó también que las decisiones de la OEA entrañaban la adopción de medidas no militares contra uno de sus miembros por parte de los demás miembros. Por ello, la aplicación de esas decisiones no requería la autorización del Consejo. La situación sería diferente, sin embargo, si las medidas analizadas se hubieran adoptado contra un Estado no miembro de esa organización regional.

Un representante señaló que era de sentido común entender que la expresión "medidas coercitivas" del artículo 53 abarcaba sólo aquellas acciones que preveían el empleo de la fuerza de manera que normalmente sería ilegítima para cualquier Estado o grupo de Estados, salvo en virtud de la autorización del Consejo de Seguridad. Las medidas adoptadas por la OEA con respecto a la República Dominicana eran actos políticos de la competencia de cualquier Estado soberano y, por consiguiente, de la competencia de los miembros de la OEA actuando colectivamente.

Tanto los copatrocinadores como los partidarios del proyecto de resolución de las tres potencias pusieron de relieve que las decisiones de la OEA se habían comunicado al Consejo de conformidad con lo dispuesto en el artículo $54^{10}$ de la Carta y las disposiciones pertinentes de la Carta de la OEA. Al decir explícitamente que las resoluciones de la OEA se transmitieran al Consejo de Seguridad sólo para su información, los Ministros de Relaciones Exteriores de los Estados miembros de la OEA expresaron claramente su parecer de que sólo era preciso notificar tales medidas a las Naciones Unidas con arreglo al artículo 54. Así, aun cuando el representante de la República Dominicana en la Conferencia de

10 "Se deberá mantener en todo tiempo al Consejo de seguridad plenamente informado de las actividades emprendidas o proyectadas de conformidad con acuerdos regionales o por organismos regionales con el propósito de mantener la paz y la seguridad internacionales”. 
San José había sostenido que las medidas acordadas no serían válidas sin la autorización del Consejo de Seguridad, los 20 Estados participantes pidieron al secretario general que informara al Consejo de Seguridad sobre las decisiones adoptadas, pero sin solicitar su autorización. Además, esas decisiones, al abarcar sólo medidas pacificadoras que eran de la competencia de los acuerdos regionales, conforme a lo establecido en la Carta, y no incluir el empleo de la fuerza, que sólo hubiera sido legítimo a tenor de una resolución del Consejo de Seguridad, únicamente tenían que ser señaladas a la atención del Consejo de Seguridad conforme a lo dispuesto en el artículo 54. La OEA, al haber sometido su informe al Consejo, había cumplido su obligación a este respecto.

En la 895a. sesión se aprobó el proyecto de resolución de las tres potencias por 9 votos contra ninguno, y 2 abstenciones, como resolución 156 (1960). El proyecto de resolución de la URSS no fue sometido a votación.

Después de la votación se expusieron interpretaciones contradictorias del significado de la decisión aprobada. El representante de la URSS declaró que, a su entender, la decisión del Consejo de tomar nota de la resolución de la OEA significaba que ninguno de los miembros se oponía a dicha resolución y que éstos la aprobaban en principio. Habría preferido, sin embargo, que esa aprobación se hubiera expresado en forma más precisa y categórica, como había propuesto su delegación. Otros representantes, sin embargo, tras hacer hincapié en que el proyecto de resolución de las tres potencias no se había presentado en virtud del artículo 53, no interpretaron la decisión del Consejo como una confirmación, que no era necesaria, de la validez de la decisión de la OEA, sino como un indicio de que el Consejo estaba de acuerdo con esa decisión. ${ }^{11}$

\section{c. Análisis del caso}

Quizá este sea el caso más cercano a la letra delTIAR, ya que se trató de la comisión de actos de agresión de un Estado americano contra otro, supuesto contemplado en el artículo 6o. de ese tratado, y el Órgano de Consulta tomó las medidas a las que se refiere el artículo 8 del mismo.

11 Naciones Unidas, Repertorio de la práctica seguida por los Órganos de las Naciones UnidasSuplemento núm. 3, Nueva York, 1971, vol. II, artículo 53, pp. 299-302, párr. 15-27. 
Es decir, las medidas tomadas fueron ajustadas al derecho interno de la OEA. Pero, ¿fueron ajustadas a la Carta de las Naciones Unidas? Tal cual surge de los debates en el Consejo de Seguridad, nadie cuestionó la oportunidad, mérito o conveniencia de las medidas, sino su legalidad a la luz del artículo 53. Sin embargo, la aprobación de la resolución 156 (1960), por la que el Consejo se limita a "tomar nota" de la resolución I de la Sexta Reunión de Consulta —aunque fue objeto de interpretaciones contradictorias - parece demostrar que el Consejo no debe "aprobar", ni "autorizar" medidas como las dispuestas contra la República Dominicana — ruptura de relaciones diplomáticas y económicas_-, y que, por lo tanto, tales medidas no constituyen "medidas coercitivas" en el sentido del artículo 53 de la Carta. Comentando el caso, De Volder comparte la falta de necesidad de autorización, basado en el argumento de que lo que los Estados pueden hacer a título individual también lo pueden hacer colectivamente:

De acuerdo con Zwanenburg, "esta opinión es fortalecida por el argumento de que los Estados individuales son siempre libres de terminar las relaciones económicas”. Sería entonces extraño argumentar que cuando los Estados individuales se organizan en grupo, esta libertad deja de existir, dado que las sanciones económicas forman parte de las medidas coercitivas que requieren la autorización del Consejo de Seguridad. ${ }^{12}$

Este primer caso fue importante porque, como veremos, se citó como precedente en las sucesivas oportunidades en que se planteó la interpretación del artículo 53.

B. El caso de Cuba en la Octava Reunión de Consulta

a. La cuestión en la Octava Reunión de Consulta

En noviembre de 1961, el gobierno de Colombia solicitó la convocatoria de la Reunión de Consulta de Ministros de Relaciones Exteriores en

12 De Volder, Eefje, Regionalism under the United Nations Framework. Exploring the limits and possibilities for regional enforcement action under the UN Charter with a special focus on Chapter VIII UN Charter, http://arno.uvt.nl/show.cgi?fid=114833, p. 28. 
virtud del artículo 6 delTIAR, para considerar "las amenazas a la paz y a la independencia política de los Estados Americanos que puedan surgir de la intervención de potencias extracontinentales encaminadas a quebrantar la solidaridad americana”, clara alusión a los intereses soviéticos en la Revolución cubana y a la proclamación del gobierno cubano como marxista-leninista. La Octava Reunión de Consulta tuvo lugar en Punta del Este en enero de 1962, aprobándose varias resoluciones, entre ellas la resolución VI, por la que resolvió:

1. Que la adhesión de cualquier miembro de la Organización de los Estados Americanos al marxismo-leninismo es incompatible con el Sistema Interamericano y el alineamiento de tal gobierno con el bloque comunista quebranta la unidad y la solidaridad del Hemisferio. 2. Que el actual Gobierno de Cuba, que oficialmente se ha identificado como un gobierno marxista-leninista, es incompatible con los principios y propósitos del Sistema Interamericano. 3. Que esta incompatibilidad excluye al actual Gobierno de Cuba de su participación en el Sistema Interamericano.

Y la resolución VIII, por la que resolvió:

1. Suspender inmediatamente el comercio y tráfico de armas e implementos de guerra de cualquier índole con Cuba. 2. Encargar al Consejo de la Organización de los Estados Americanos que, a la luz de las circunstancias y consideradas debidamente las limitaciones constitucionales o legales de todos y cada uno de los Estados Miembros, estudie la posibilidad y conveniencia de extender la suspensión del comercio y tráfico de armas a otros artículos, prestando especial atención a los de importancia estratégica. ${ }^{13}$

\section{b. Debates en el Consejo de Seguridad}

Por carta de fecha 22 de febrero de 1962, el gobierno de Cuba denunció que el gobierno de los Estados Unidos había inducido a la OEA a adoptar contra Cuba ciertas medidas coercitivas de carácter político y económico que violaban la Carta de las Naciones Unidas y en particular

13 OEA, Acta Final de la Octava Reunión de Consulta de Ministros de Relaciones Exteriores, Punta del Este, Uruguay, 22-31 de enero de 1962. 
el párrafo 1 del artículo 53, puesto que esas medidas se habían adoptado y se estaban aplicando sin la autorización del Consejo y pedía la urgente convocatoria del Consejo.

En la 991a. sesión, durante la aprobación del orden del día, se recordó que el Consejo había examinado ampliamente, al debatirse la cuestión relativa a la República Dominicana, la relación jurídica entre la OEA y las Naciones Unidas con respecto a las decisiones adoptadas por el organismo regional. En opinión de algunos representantes, la decisión adoptada entonces se refería precisamente a las medidas adoptadas por la OEA — concernientes a las relaciones diplomáticas y económicas - que ahora denunciaba la delegación cubana. Desde entonces no se habían producido hechos nuevos, y en la carta del representante de Cuba no había nada que pudiera llevar al Consejo a revocar su decisión.

Por otra parte, se sostuvo que la cuestión sometida a la consideración del Consejo se refería a una decisión de la OEA que se apartaba directamente de los propósitos y principios de la Carta, y especialmente del artículo 53. Se dijo además que las medidas coercitivas, en el sentido del artículo 41 de la Carta, eran medidas colectivas tomadas por los Estados con objeto de obligar a otro Estado a seguir contra su voluntad una línea de conducta determinada, sin recurrir a la fuerza armada. El ejercicio de la coacción contra un Estado soberano era lícito conforme a la Carta sólo cuando el Estado, por su comportamiento, pusiera en peligro la paz y la seguridad internacionales. Ello significaba, por lo tanto, que la decisión en la cuestión del recurso a medidas coercitivas era prerrogativa exclusiva del Consejo de Seguridad.

En la misma sesión se puso a votación el orden del día provisional que, no habiendo obtenido el voto afirmativo de siete miembros, quedó desechado. ${ }^{14}$

Por carta del 8 de marzo de 1962, el representante de Cuba señaló que a raíz de algunas decisiones acordadas en la Octava Reunión de Consulta, se habían aplicado contra Cuba medidas coercitivas sin la autorización del Consejo de Seguridad, prescrita por el artículo 53. Se pedía, pues, que se convocara urgentemente a sesión al Consejo.

${ }_{14}$ Naciones Unidas, op. cit., p. 302-303, párr. 28-31. 
En la 992a. sesión el representante de Cuba presentó un proyecto de resolución en virtud del cual el Consejo de Seguridad solicitaba de la Corte Internacional de Justicia una opinión consultiva sobre, entre otras, las cuestiones siguientes:

2. Si la Organización de los Estados Americanos tiene, de acuerdo con la Carta de las Naciones Unidas, el derecho como organismo regional de aplicar las medidas coercitivas previstas en el Artículo 53 de la Carta de las Naciones Unidas, sin autorización del Consejo de Seguridad. 3. Si bajo el término de "medidas coercitivas" mencionadas en el Artículo 53 de la Carta de las Naciones Unidas, pueden considerarse implicadas las medidas previstas en el Artículo 41 de la Carta de las Naciones Unidas. Si la relación de estas medidas en el Artículo 41 es exhaustiva.

En apoyo del proyecto, un representante expresó el parecer de que las decisiones de la OEA entrañaban sanciones políticas y económicas y, en cuanto tales, esas decisiones constituían medidas coercitivas contra Cuba. Tales medidas violaban el artículo 53 de la Carta, ya que habían sido adoptadas y se estaban aplicando sin autorización del Consejo de Seguridad. Las únicas decisiones de un organismo regional que requerían la aprobación del Consejo, conforme al artículo 53, eran las que entrañaban el empleo de medidas coercitivas. Esas medidas eran las enumeradas en el artículo 41 de la Carta, y posiblemente también otras medidas, cuyo propósito era el de obligar a algunos Estados a someterse a la voluntad de otros Estados. Aunque un Estado podía tomar contra otro algunas de las medidas mencionadas en el artículo 41, tales como la ruptura de relaciones diplomáticas y la interrupción de las relaciones económicas, la naturaleza de esas medidas cambiaba cuando se adoptaban en virtud de una decisión de un grupo de Estados organizados en forma de organismo regional o de otro tipo. Adoptadas colectivamente, esas medidas se convertían en medidas coercitivas contra otro Estado y constituían una acción política cuyo alcance y significado eran completamente diferentes de los que podrían tener esas acciones ejecutadas aisladamente por un Estado con respecto a otro Estado. Evidentemente, un Estado no podía someter a un bloqueo a todos los demás Estados. Lo mismo podía decirse de la ruptura de relaciones diplomáticas. Un Estado, si bien podía romper sus relaciones diplomáticas con otro Es- 
tado, no estaba en condiciones de crear un vacío político en torno a ese Estado. Ahora bien, si la misma medida era adoptada por un grupo de Estados, particularmente en una organización regional o de otro tipo, se trataba de algo muy distinto que podía acarrear consecuencias diferentes y mucho más graves. Ésta era la razón por la cual la Carta contenía una disposición según la cual las organizaciones regionales no estaban facultadas para aplicar medidas coercitivas sin la autorización del Consejo de Seguridad. Ese representante recordó además que el Consejo había sancionado la adopción por la OEA de medidas coercitivas contra la República Dominicana, cumpliendo así, respecto de esas medidas, la función que le encomendaba el artículo 53.

Otro partidario del proyecto observó que no había ninguna indicación clara que permitiera determinar si la autorización del Consejo de Seguridad sólo era necesaria cuando se tratara de medidas que requerían el empleo de la fuerza armada, conforme a lo dispuesto en el artículo 42, ni si esa autorización sólo era necesaria para medidas que normalmente serían contrarias al derecho internacional y no en el caso de medidas comprendidas en la esfera de competencia de un Estado. Por consiguiente, seguía habiendo motivos de duda razonable en cuanto al significado de las "medidas coercitivas" previstas en el artículo 53, y por ello debía pensarse en la conveniencia de solicitar de la Corte Internacional de Justicia una opinión consultiva.

Los representantes que se opusieron al proyecto sostenían que las decisiones de Punta del Este no constituían medidas coercitivas en el sentido del artículo 53, sino que eran medidas que cualquier Estado podía tomar legalmente, en forma individual o colectiva, sin autorización de nadie. Además, nada en las decisiones justificaba que el Consejo invocara el artículo 53, y la OEA cumplía con sus obligaciones ante el Consejo al comunicar, conforme al artículo 54, las medidas que había adoptado. Un representante declaró que las decisiones comunicadas al Consejo no requerían la aprobación de éste, sino el reconocimiento oficial de lo actuado. Observó además que la expresión "medidas coercitivas" empleada en el artículo 53 había sido motivo principal de controversia. La expresión inglesa (enforcement action) era mucho más fuerte que el término español de “coacción”, que significaba el empleo de la fuerza o la violencia. Otro tanto sucedía con el texto francés, en el que 
la expresión mesures coercitives procedía del verbo contraindre, que significaba "empleo de la violencia". Ese representante señaló además que la propia Carta hacía un distingo, en los artículos 41 y 42, entre los dos tipos de medidas que podía adoptar el Consejo: las que implicaban el uso de la fuerza armada y otras medidas que no tenían ese carácter. Por otra parte, si bien los artículos 44 y 45 se referían expresamente al uso de la fuerza, el artículo 45 relacionaba directamente la "acción coercitiva internacional" con el empleo de las fuerzas armadas. La finalidad del artículo 53 era indudablemente prohibir el "uso de la fuerza" por organismos regionales, sin autorización del Consejo, con la sola excepción de la legítima defensa. Por lo tanto, en cuanto concernía al artículo 53, no se producía ninguna consecuencia en relación con las medidas adoptadas en Punta del Este, que correspondían exclusivamente a la jurisdicción interna del organismo regional y habían sido adoptadas por su órgano competente.

Otro representante dijo que la expresión "medidas coercitivas" designaba una acción coactiva que implicaba el uso de fuerza física. El tipo de acción previsto en el artículo 41, esto es, las "medidas que no impliquen el uso de la fuerza armada”, no requerían la autorización del artículo 53. En el artículo 54 se indicaba que las "actividades emprendidas... por organismos regionales con el propósito de mantener la paz y la seguridad internacionales" debían comunicarse al Consejo; cuando ese artículo se examinaba junto con los artículos que lo precedían, era evidente que tales actividades incluían todas las medidas que no entrañaban el uso de la fuerza y, por lo tanto, que el artículo aplicable a todas las medidas de esa naturaleza era el artículo 54 y no el artículo 53.

A juicio de algunos representantes, la cuestión había sido resuelta por el propio Consejo en 1960. Se señaló que la resolución aprobada en esa ocasión no había definido, quizá lo que constituía medidas coercitivas con arreglo al artículo 53, pero había dejado definitivamente establecido que las medidas adoptadas contra la República Dominicana no quedaban comprendidas en el ámbito de ese artículo. Así pues, esos representantes sostenían la tesis de que si medidas de la naturaleza y el alcance de las adoptadas contra la República Dominicana no correspondían al concepto de medidas coercitivas con arreglo al artículo 53, lo mismo podía decirse de las adoptadas en Punta del Este, que tenían un alcance mucho más restringido. 
En la 998a. sesión, el proyecto de resolución fue rechazado por 7 votos contra 2 y una abstención. Uno de los miembros no participó en la votación. ${ }^{15}$

c. Análisis del caso

Las resoluciones de Punta del Este quizá sean las más cuestionadas en la historia de la OEA, y no pretendemos desde aquí hacer un control estricto de su legalidad sino analizar cómo se relacionan con el artículo 53 de la Carta de las Naciones Unidas. En efecto, se adoptaron en Punta del Este dos clases de medidas: las destinadas a la exclusión del gobierno cubano de la participación en las actividades de la Organización (resolución $\mathrm{VI}$ ), y las que implican la ruptura de relaciones económicas (resolución VIII). Las primeras hacen al funcionamiento de la organización y a las relaciones con sus miembros, y deben ser resueltas de conformidad a lo establecido en su propio ordenamiento jurídico, escapando en principio al concepto de "medidas coercitivas" del artículo 53. ${ }^{16}$ Las segundas, en cambio, corresponden al elenco de medidas que figura en el artículo 8 del TIAR, y de la actuación del Consejo de Seguridad surge implícitamente que se mantuvo el alcance fijado a las "medidas coercitivas" en 1960, es decir, aparentemente limitado a las que impliquen el uso de la fuerza, aunque se debe destacar que una opinión consultiva de la Corte Internacional de Justicia habría dado una respuesta autorizada y con fundamento jurídico sobre la cuestión.

Por lo tanto, no hay — según la práctica del Consejo- objeción constitucional desde el artículo 53 de la Carta de las Naciones Unidas a las acciones emprendidas por la OEA, aunque es difícil afirmar que las mismas hayan sido tomadas en un marco de estricta legalidad de conformidad con la Carta de la OEA y el TIAR. ${ }^{17}$

15 Naciones Unidas, op. cit., pp. 303-306, párrs. 32-44.

16 No podemos olvidar aquí, no obstante, que en esa época la Carta de la OEA no preveía ningún mecanismo de suspensión de los miembros, como sí lo hace el actual artículo 9.

17 Sobre todo teniendo en cuenta el principio de no intervención (de profunda raigambre en el Sistema Interamericano), la libre determinación de los pueblos y el derecho soberano de cada Estado a determinar su forma de gobierno, pero ello no es materia de estudio en este artículo. 


\section{La"Crisis de los Misiles"}

a. La cuestión en el Consejo Permanente

El 23 de octubre de 1962, con motivo de la crisis desatada por la instalación de misiles soviéticos en Cuba, el Consejo Permanente de la OEA, actuando provisionalmente como Órgano de Consulta, aprobó una resolución por la cual resolvió:

1. Instar a que se desmantelen inmediatamente y se retiren de Cuba todos los proyectiles y cualesquiera otras armas con capacidad ofensiva. 2. Recomendar a los Estados Miembros, de conformidad con los artículos 6 y 8 del Tratado Interamericano de Asistencia Recíproca, que adopten todas las medidas individuales y colectivas, incluso el empleo de la fuerza armada, que consideren necesarias para asegurar que el Gobierno de Cuba no pueda continuar recibiendo de las potencias chino-soviéticas, pertrechos y suministros militares que amenacen la paz y la seguridad del Continente, y para impedir que los proyectiles en Cuba con capacidad ofensiva se conviertan en cualquier momento en una amenaza activa contra la paz y la seguridad del Continente. 3. Informar al Consejo de Seguridad de las Naciones Unidas sobre esta Resolución, de conformidad con el Artículo 54 de la Carta de las Naciones Unidas. ${ }^{18}$

\section{b. Debates en el Consejo de Seguridad}

La cuestión fue introducida en el Consejo de Seguridad en virtud de las denuncias presentadas por Cuba, la URSS y los Estados Unidos (22 y 23 de octubre de 1962), aunque hubo poco debate en relación con el artículo 53. En la 1022a. sesión fue implícitamente mencionado por el representante de Cuba cuando afirmó que al declarar su intención de arrastrar en sus actos de agresión contra Cuba a la Organización de los Estados Americanos, a la cual obligan ya a aplicar sanciones colectivas contra Cuba, los Estados Unidos usurpan abiertamente las prerrogativas del

18 Naciones Unidas: Carta del 23 de octubre de 1962 dirigida al secretario general interino de las Naciones Unidas por el secretario general de la Organización de los Estados Americanos, Documento S/5193, Nueva York, 1962. 
Consejo de Seguridad, que es el único facultado para aplicar medidas coercitivas. ${ }^{19}$ En la 1024a. sesión, el representante de Ghana declaró que al presentar la tesis de su gobierno, el representante de los Estados Unidos había dado la impresión de que consideraba esas medidas, ratificadas por el Consejo de la OEA, como enteramente dependientes de la competencia de esa organización, pero que su delegación discrepaba de ese parecer. Aunque los organismos regionales tienen derechos y deberes reconocidos por la Carta de las Naciones Unidas y cuyo pleno ejercicio no debe impedirse, esos derechos y deberes no entrañan en modo alguno prioridad absoluta sobre la jurisdicción de las Naciones Unidas. Recordó que la delegación de los Estados Unidos había expresado el parecer de que las medidas de aplicación son las coercitivas del tipo previsto en el artículo 42 de la Carta, y que, por lo tanto, está claro que la acción prevista por los Estados Unidos debe considerarse como medida coercitiva, que según el artículo 53 es inadmisible sin la autorización del Consejo de Seguridad. ${ }^{20}$

c. Análisis del caso

El escaso debate en el Consejo sobre la aplicación del artículo 53 no permite extraer muchas consideraciones al respecto. Lo que para nosotros es indudable es que las medidas recomendadas por la OEA implicaban el uso de la fuerza, toda vez que surge de la misma resolución del Consejo Permanente, y la eufemística denominación de "cuarentena" no modifica en nada su naturaleza. ${ }^{21}$ En tal sentido, se trató de medidas coercitivas que debieron requerir la autorización del Consejo de Seguridad en virtud del artículo 53.1 de la Carta.

Sin embargo, el caso es utilizado por la doctrina para señalar la cuestión de si la autorización del Consejo sólo es necesaria cuando las me-

19 Consejo de Seguridad: Acta oficial de la 1022a. sesión. Documento S/PV.1022, Nueva York, Naciones Unidas, 1962, párr. 172.

20 Consejo de Seguridad: Acta oficial de la 1024a. sesión. Documento S/PV.1024, Nueva York, Naciones Unidas, 1962, párrs. 107-109.

21 Hakimi, Monica, "To condone or condemn? Regional enforcement actions in the absence of Security Council authorization”, Vanderbilt Journal of Transnational Law, Vanderbilt University, School of Law, 2007. 
didas coercitivas son objeto de una decisión vinculante adoptada por un organismo regional, o también cuando ese organismo se limita a la adopción de una recomendación, como hizo en el caso el Consejo Permanente, ya que los Estados Unidos plantearon que sólo debe recabarse la autorización en el primer caso, de acuerdo a lo resuelto por la Corte Internacional de Justicia en el asunto Ciertos gastos de las Naciones Unidas. Repasemos entonces lo que dijo la Corte:

La Corte considera que la acción de que trata el párrafo 2 del Artículo 11 [de la Carta] es una acción coercitiva. En virtud de la primera frase de este párrafo, que se aplica ... sino también a casos concretos sometidos por un Estado a la Asamblea General con arreglo al Artículo 35, la Asamblea queda facultada para organizar operaciones de mantenimiento de la paz por medio de recomendaciones dirigidas a Estados, al Consejo de Seguridad o a ambos, y a petición de los Estados interesados o con su consentimiento. Este poder de la Asamblea General es un poder especial que no menoscaba en modo alguno sus poderes generales conforme a los Artículos 10 o 14, con la salvedad indicada en la última frase del párrafo 2 del Artículo 11. Esta última frase dice que cuando se requiera "acción", la Asamblea General referirá la cuestión al Consejo de Seguridad. La palabra "acción” debe significar una acción de la competencia exclusiva del Consejo de Seguridad. ${ }^{22}$

Como surge del pasaje citado y bien lo señala Hakimi, ${ }^{23}$ la opinión de la Corte no apoya el argumento de los Estados Unidos por tratarse de un supuesto totalmente diferente: la aprobación por parte de la Asamblea General de operaciones de mantenimiento de la paz, y no de la implementación de medidas coercitivas por los organismos regionales (de hecho, la Corte ni siquiera menciona el artículo 53).

A mayor abundamiento, hacemos nuestro los argumentos de Villani, cuando expresa:

[L]a autorización del Consejo de Seguridad es indispensable también en el caso de las recomendaciones relativas a las medidas que impliquen el uso de la fuerza armada. En primer lugar ... no es razonable considerar que la acción armada

22 CIJ: Certaines dépenses des Nations Unies (article 17, paragraphe 2, de la Charte), Avis consultatif du 20 juillet 1962. C. I.J . Recueil 1962, pp. 151, 164 y 165.

23 Hakimi, Monica, op. cit. 
de los Estados miembros de una organización regional, que estaría prohibida si se tomara como la aplicación de una decisión de esa organización, debería ser permitida (y por lo tanto no requeriría autorización en virtud del artículo 53) si esa acción se basara en la adhesión espontánea a la recomendación. En segundo lugar, debe recordarse que el artículo 2, párrafo 4 de la Carta prohíbe no solo el uso, sino también la amenaza de la fuerza; entonces, una recomendación de tomar medidas armadas necesariamente implica una amenaza de la fuerza. Así, sólo la autorización del Consejo de Seguridad en virtud del párrafo del artículo 53 párrafo 1 puede hacer esa amenaza legal (como en el caso del uso de la fuerza). Por último, el carácter coercitivo de las medidas armadas, incluso si son objeto de una recomendación, puede verse claramente desde el punto de vista del Estado contra los que se dirigen: de hecho, para un Estado, no hace diferencia alguna si los Estados que actúan en su contra lo hacen voluntariamente al adherirse a una recomendación o si son obligados a hacerlo en virtud de una decisión vinculante de una organización regional. ${ }^{24}$

\section{El caso de la República Dominicana en la Décima Reunión de Consulta}

\section{a. La cuestión en la Décima Reunión de Consulta}

En abril de 1965, a solicitud del gobierno de Chile y en virtud de la Carta de la OEA, se convocó a una Reunión de Consulta de Ministros de Relaciones Exteriores para tratar el tema "Grave situación creada por la lucha armada en la República Dominicana”. La Décima Reunión de Consulta se celebró en Washington DC. Por resolución III (de 6 de mayo de 1965), resolvió:

1. Solicitar de los gobiernos de los Estados Miembros que lo deseen y estén en condiciones de hacerlo, que, dentro de sus posibilidades y en la medida en que puedan hacerlo, suministren a la Organización de los Estados Americanos contingentes terrestres, navales, aéreos o de policía, a fin de formar con ellos una fuerza interamericana que funcionará bajo la autoridad de esta Décima Reunión de Consulta. 2. Esta Fuerza tendrá como único fin, dentro de un espíritu de imparciali-

24 Villani, Ugo, op. cit., pp. 541 y 542. 
dad democrática, colaborar en la restauración de la normalidad en la República Dominicana, el mantenimiento de la seguridad de sus habitantes, la inviolabilidad de los derechos humanos y el establecimiento de un clima de paz y conciliación que permita el funcionamiento de las instituciones democráticas en dicha República. ${ }^{25}$

b. Debates en el Consejo de Seguridad

Por carta del 1o. de mayo de 1965, el representante de la URSS solicitó que se convocara con urgencia una reunión del Consejo de Seguridad "para examinar la cuestión de la intervención armada de los Estados Unidos en los asuntos internos de la República Dominicana”. En la 1202a. sesión, el representante de los Estados Unidos informó al Consejo sobre la resolución III de la Reunión de Consulta.

En opinión de algunos representantes, el desembarco de tropas estadounidenses y la participación de éstas en la represión de la lucha por la libertad y la independencia del pueblo en ese territorio sólo podían considerarse como un acto de agresión directa y una intervención flagrante en los asuntos internos de un Estado soberano. La acción de los Estados Unidos, y posteriormente de la OEA, entrañaba el uso de fuerzas armadas y, como tal, constituían medidas coercitivas por cuanto suponía un intento de imponer por la fuerza una línea de conducta determinada a un Estado independiente y soberano que ni siquiera había sido acusado de agresión. Más aún, la OEA no estaba facultada para resolver acerca de la adopción de medidas coercitivas y mucho menos para aplicar tal decisión sin la autorización del Consejo de Seguridad, en virtud del artículo 53.

En la 1204a. sesión, el representante del Uruguay presentó un proyecto de resolución, en el cual el Consejo de Seguridad invitaba a la OEA a que mantuviera pronta y completamente informado al Consejo acerca de las acciones que tomara la Organización con respecto a la situación existente en la República Dominicana y, asimismo invitaba a la OEA a cooperar con el secretario general de las Naciones Unidas a los efectos del cumplimiento de dicha resolución. Al presentar su proyecto observó que la armonización de las funciones de las Naciones Unidas

25 OEA, "Acta Final de la Décima Reunión de Consulta de Ministros de Relaciones Exteriores”, Washington D. C., 1o. de mayo de 1965-6 de marzo de 1970. 
con las de los organismos regionales era un problema difícil que sólo se había planteado recientemente. Por ello, su proyecto de resolución no tenía como finalidad tratar ese problema, y sólo se refería de un modo general, en el tercer párrafo del preámbulo, a las "disposiciones pertinentes del Capítulo VIII" sin mencionar disposiciones particulares de ese Capítulo que pudieran dar origen a diferencias de criterio.

Sin embargo, un miembro se opuso, basándose en que no podía apoyar ninguna disposición que contuviera cualquier expresión directa o indirecta de aprobación de las medidas de la OEA, que eran contrarias a la Carta de las Naciones Unidas porque el organismo regional no había recibido ningún mandato del Consejo de Seguridad, según lo dispuesto en el artículo 53, para aplicar medidas coercitivas.

En la 1216a. sesión, el proyecto de resolución fue rechazado por no haber obtenido el voto afirmativo de siete miembros.

En el debate ulterior, varios representantes opinaron que el establecimiento y funcionamiento de una Fuerza Interamericana y la acción de la OEA con respecto a la situación en la República Dominicana no constituían una aplicación de medidas coercitivas en el sentido del párrafo 1 del artículo 53. Sostuvieron que la Fuerza se había creado únicamente con el fin de ayudar a restaurar las condiciones normales en la República Dominicana y de mantener la seguridad de sus habitantes y la inviolabilidad de los derechos humanos. Así pues, la Fuerza Interamericana no se empleaba para forzar al gobierno dominicano o hacer concesiones o para exigir de ese gobierno que adoptara o no determinada línea de conducta. Por consiguiente, no se podía calificar a los esfuerzos colectivos de la OEA como medidas coercitivas con arreglo al artículo 53. Las disposiciones enunciadas en los artículos 52 y 54 eran mucho más pertinentes al caso que las del artículo 53.

Sin embargo, otros dos representantes pusieron en tela de juicio que la OEA hubiera actuado de conformidad con las disposiciones de la Carta. Recordaron que la Carta de las Naciones Unidas no autorizaba una acción militar del tipo de la realizada en la República Dominicana, ya fuera de carácter unilateral o regional. No se podían aplicar medidas coercitivas en virtud de acuerdos regionales sin la autorización del Consejo de Seguridad. Más aún, la intervención y el uso de la fuerza por parte de un Estado o de un grupo de Estados eran siempre con- 
trarios a la legalidad internacional, a menos que estuvieran justificados por normas tales como las enunciadas en el Capítulo VII de la Carta. En cualquier caso, la intervención militar en la República Dominicana no podía considerarse como una "operación de mantenimiento de la paz", puesto que faltaba un requisito indispensable, a saber, el consentimiento de la parte interesada. Por consiguiente, aunque se reconociera el carácter multilateral de la operación, si, tras un examen cuidadoso, se determinara que las medidas aplicadas en la República Dominicana eran coercitivas con arreglo a las disposiciones de la Carta, la única consecuencia que emanaría de su "regionalización" sería la de hacer aplicables las disposiciones del artículo 53 de la Carta.

Por otra parte, se sostuvo que la acción emprendida por la OEA en la República Dominicana no constituía una aplicación de medidas coercitivas, como tampoco lo fueron las acciones emprendidas por las Naciones Unidas en Chipre, el Congo o el Oriente Medio, ni podía ponerse en duda la competencia o la jurisdicción de la OEA para ocuparse del problema en la medida en que sus acciones se ajustaran a la Carta. ${ }^{26}$

\section{c. Análisis del caso}

Las medidas adoptadas por la OEA en esta cuestión son de difícil caracterización. Si se hubiera tratado de una intervención armada (y que no fuera tomada en legítima defensa colectiva) no cabría duda de que estaríamos ante una "medida coercitiva" del artículo 53 para la que se habría necesitado la autorización del Consejo de Seguridad. Así lo sostiene Vargas Carreño:

Si bien la intervención armada de un Estado en otro, aunque se invoquen razones humanitarias, está prohibida por el actual derecho internacional, igualmente tal prohibición se extiende a la realizada por un conjunto de Estados... [T]al tipo de intervención no puede ser llevada a cabo por una organización regional si no cuenta con la autorización del Consejo de Seguridad... [D]e acuerdo al artículo 53, párrafo 1 de la Carta, la aplicación de medidas coercitivas por acuerdos o por organismos regionales requieren la autorización del Consejo de Seguridad. Por

26 Naciones Unidas, op. cit., pp. 306-308, párrs. 45-54. 
ello no podemos si no expresar nuestras reservas a la intervención autorizada por la Décima Reunión de Consulta de Ministros de Relaciones Exteriores de la OEA el año 1965 en la República Dominicana... ${ }^{27}$

Por otro lado, afirmar que se trató de una "operación de mantenimiento de la paz" es inexacto, al faltar la base consensual que constituye uno de los pilares básicos de este tipo de operaciones, resultando de aplicación en este caso lo afirmado por la Corte Internacional de Justicia en su opinión consultiva en Ciertos gastos, citada supra (pero no es válido el argumento de que tales operaciones no están previstas en la Carta de la OEA ya que tampoco están previstas en la Carta de la ONU y ello no le ha impedido desplegarlas en numerosas oportunidades).

La indefinición del Consejo impide una conclusión satisfactoria, pero debemos notar que ha sido práctica constante del Consejo de Seguridad no considerar a las operaciones de mantenimiento de la paz como "medidas coercitivas", limitándose a tomar nota de su despliegue, salvo que requieran hacer uso de la fuerza para cumplir su mandato, en cuyo caso deben contar con su autorización.

\section{E. El caso de Haití en la Reunión ad hoc de Ministros de Relaciones Exteriores}

a. El marco jurídico: la Resolución 1080

El 5 de junio de 1991, la Asamblea General de la OEA aprobó la resolución 1080 (XXI-O-91), en la que, considerando, entre otras cosas, "Que el preámbulo de la Carta de la Organización de los Estados Americanos, establece que la democracia representativa es condición indispensable para la estabilidad, la paz y el desarrollo de la región” y “Que según lo establece la Carta, uno de los propósitos fundamentales de la OEA es promover y consolidar la democracia representativa dentro del respeto al principio de no intervención”, resolvió

27 Vargas Carreño, Edmundo: "El principio de no intervención y su vigencia en el derecho internacional del siglo XXI", en Méndez Silva, Ricardo (coord.), Derecho y seguridad internacional. Memoria del Congreso Internacional de Culturas y Sistemas Jurídicos Comparados, México, UNAM, 2005, p. 29. 
1. Instruir al Secretario General que solicite la convocación inmediata del Consejo Permanente en caso de que se produzcan hechos que ocasionen una interrupción abrupta o irregular del proceso político institucional democrático o del legítimo ejercicio del poder por un gobierno democráticamente electo en cualquiera de los Estados miembros de la Organización para, en el marco de la Carta, examinar la situación, decidir y convocar una reunión ad hoc de ministros de relaciones exteriores, o un período extraordinario de sesiones de la Asamblea General, todo ello dentro de un plazo de 10 días. 2. Expresar que la reunión ad hoc de ministros de relaciones exteriores o el período extraordinario de sesiones de la Asamblea General tenga por objeto analizar colectivamente los hechos y adoptar las decisiones que se estime apropiadas, conforme a la Carta y el derecho internacional».

El presupuesto para la actuación de la reunión ad hoc de ministros de relaciones exteriores o un periodo extraordinario de sesiones de la Asamblea General es, entonces, "que se produzcan hechos que ocasionen una interrupción abrupta o irregular del proceso político institucional democrático o del legítimo ejercicio del poder por un gobierno democráticamente electo en cualquiera de los Estados miembros”. Las medidas que se pueden tomar no están especificadas en la resolución, que se limita a decir que sean "apropiadas, conforme a la Carta y el derecho internacional”; ello incluye, a nuestro entender, medidas como las mencionadas en el artículo 8 delTIAR.

\section{b. La cuestión en la Reunión ad hoc}

La primera vez que se aplicó el mecanismo de la resolución 1080 fue en septiembre de 1991, cuando el Consejo Permanente, "ante la gravedad de los acontecimientos ocurridos en Haiti”" (que incluían el derrocamiento del presidente constitucional, Jean Bertrand Aristide, y la creación de un gobierno de facto), convocó a una Reunión ad hoc de Ministros de Relaciones Exteriores, la que, en su resolución MRE/ RES.1/91, resolvió, entre otras cosas:

5. Recomendar, con el debido respeto a la política de cada uno de los Estados miembros en materia de reconocimiento de Estados y gobiernos, una acción que procure el aislamiento diplomático de quienes detentan de hecho el poder en 
Haití. 6. Recomendar a todos los Estados que suspendan sus vínculos económicos, financieros y comerciales con Haití, así como la ayuda y cooperación técnica que fuera del caso. ${ }^{28}$

En la resolución MRE/RES.2/91, resolvió: "Exhortar a los Estados miembros a que en forma inmediata procedan al congelamiento de los activos del Estado haitiano y apliquen un embargo comercial a Haití, salvo excepciones de carácter humanitario". ${ }^{29}$

\section{c. Debates en el Consejo de Seguridad}

Por carta del 7 de junio de 1993, el representante de Haití solicitó al Consejo de Seguridad que tuviera a bien dar carácter universal y obligatorio a las sanciones adoptadas contra las autoridades de facto en ese país en la reunión especial de Ministros de Relaciones Exteriores de la OEA y cuya aplicación se había recomendado a la comunidad internacional en diferentes resoluciones de la Asamblea General de las Naciones Unidas, y que diera prioridad al embargo de petróleo y los derivados de éste, así como del suministro de armas y municiones. ${ }^{30}$

En su 3238a. sesión, el Consejo incluyó la cuestión en su orden del día. La representante del Canadá sostuvo que había que reconocer que la OEA dispone de medios limitados. El embargo de la OEA al comercio con Haití no era obligatorio para los países que no eran miembros de esa organización, reduciendo así sus consecuencias y permitiendo que el régimen ilegal de Puerto Príncipe se aferrara al poder. Reconociendo esa realidad, la OEA estimó necesario pedir el apoyo de las Naciones Unidas.

28 Naciones Unidas, Carta del 3 de octubre de 1991 dirigida al secretario general por el Representante Permanente de Honduras ante las Naciones Unidas, Apéndice, Documento A/46/231, Nueva York, 1991.

29 Naciones Unidas, Carta del 9 de octubre de 1991 dirigida al secretario general por el Representante Permanente de Honduras ante las Naciones Unidas, Apéndice, Documento A/46/550-S/23127, Nueva York, 1991.

30 Naciones Unidas, Carta del 7 de junio de 1993 dirigida al presidente del Consejo de Seguridad por el representante permanente de Haití ante las Naciones Unidas, Documento S/25958, Nueva York, 1993. 
A continuación se sometió a votación un proyecto de resolución presentado por los Estados Unidos, Francia y Venezuela, que resultó aprobado por unanimidad como resolución 841 (1993). Mediante esa resolución, el Consejo, habiendo recibido la carta del representante de Haití, tomando nota de las resoluciones de la Reunión ad hoc, recordando las disposiciones del Capítulo VIII de la Carta,

Considerando que la solicitud antes mencionada del representante de Haití, formulada en el contexto de las medidas conexas adoptadas previamente por la Organización de los Estados Americanos y por la Asamblea General de las Naciones Unidas, define una situación singular y excepcional que justifica la adopción de medidas extraordinarias por el Consejo en apoyo de los esfuerzos desplegados en el marco de la Organización de los Estados Americanos, Determinando que, en estas circunstancias singulares y excepcionales, la continuación de esta situación amenaza a la paz y seguridad internacionales en la región, Actuando, en consecuencia, en virtud del Capítulo VII de la Carta,

decidió imponer un embargo de armas y un embargo de petróleo contra el gobierno de facto de Haití.

Después de la votación, el presidente declaró que la aprobación de esa resolución se justificaba por la situación singular y excepcional prevaleciente en Haití, y que no debía considerarse que constituyera un precedente. Ello fue ratificado por los representantes de Pakistán y China.

El representante de Venezuela afirmó que las medidas tomadas de acuerdo con las resoluciones de la OEA de embargo de petróleo y de armas no eran suficientes. Las disposiciones del embargo no eran acatadas por no ser obligatorias. La acción que el Consejo decidió se inscribía sin duda en el marco de la cooperación entre las Naciones Unidas y un organismo regional, en este caso la Organización de los Estados Americanos. Era evidente que la única forma de fortalecer el embargo era hacerlo universal y obligatorio, y para ello resultaba indispensable la acción del Consejo de Seguridad.

Para el representante de Brasil, la resolución aprobada dejaba bien en claro que la situación en Haití era única y excepcional. Ese singularismo y carácter excepcional se definían por la conjunción de una serie de factores, en particular la petición hecha por el gobierno legítimo de 
Haití de que el Consejo de Seguridad hiciera universales y obligatorias las medidas recomendadas por la OEA. Otro factor que singularizaba la crisis era el hecho de que ya la OEA y la Asamblea General habían tomado medidas en esta misma dirección. Esa acción proporcionaba un marco de referencia que permitía la consideración extraordinaria del asunto por el Consejo de Seguridad y la aplicación igualmente extraordinaria de las medidas previstas en el Capítulo VII de la Carta. ${ }^{31}$

\section{d. Análisis del caso}

Las circunstancias que rodearon la aprobación de la resolución 841 (1993) fueron verdaderamente "singulares y excepcionales", ya que se trataba de un asunto que, en principio, era de la jurisdicción interna de un Estado, y en el cual el gobierno legítimo de ese Estado requería que se aplicaran sanciones contra las autoridades de facto. Ésa fue la razón por la que varios Estados insistieron en el carácter excepcional de la cuestión y en que no constituía un precedente.

Yendo a la materia de análisis en este artículo, la resolución 841 (1993) puede inducir a confusión en lo que respecta al alcance de las “medidas coercitivas" del artículo 53. Así, afirmaba Cardona Llorens antes de revisar su postura como comentamos supra:

los acuerdos u organismos regionales no pueden "decidir" ningún tipo de medida coercitiva contra un Estado sin previa autorización del Consejo de Seguridad. Así, por ejemplo, la OEA, tras adoptar diversos acuerdos para intentar solventar la crisis en Haití producida por el golpe de Estado contra el Presidente Aristide, recomendó a sus Estados miembros un embargo económico contra Haití, pero dicho embargo no fue obligatorio hasta que el C. de S., a través de la resolución 841 (1993) lo asumió y universalizó. ${ }^{32}$

Es decir, pareciera a primera vista que el Consejo, al aprobar la resolución 841 (1993), incluyó implícitamente las medidas que no implican

31 Consejo de Seguridad, Acta taquigráfica provisional de la 3238a. sesión, Documento S/ PV.3238, Nueva York, Naciones Unidas, 1993.

32 Cardona Llorens, Jorge, op. cit., p. 235. 
el uso de la fuerza en el concepto de "medidas coercitivas" del artículo 53, haciendo necesaria entonces su autorización.

Sin embargo, no ha de ser esa la interpretación correcta. En primer lugar, el Consejo en ningún momento "autoriza” ni "aprueba” las medidas dispuestas por la OEA, sino que se limita a "tomar nota" de las mismas. En segundo lugar, las medidas adoptadas por el Consejo, aunque, "en consonancia con el embargo comercial adoptado por la Organización de los Estados Americanos", son autónomas, tomadas en virtud del Capítulo VII de la Carta, y sin citar el artículo 53. Finalmente, las mismas obedecieron a una solicitud expresa del gobierno legítimo de un Estado y no a un pedido de autorización de la misma OEA, quien por su parte había tomado las medidas un año y medio antes sin requerir la aprobación del Consejo de Seguridad. Entonces, ¿cuál fue el objeto de la resolución 841 (1993)? No otro que "transformar" el embargo de la OEA en medidas del artículo 41 de la Carta, y por lo tanto universales y obligatorias.

Ello significa, a contrario sensu, que las medidas dispuestas por la OEA sólo tienen alcance regional y carecen de obligatoriedad. El primer efecto es de toda lógica, por cuanto un tratado (en este caso, la Carta de la OEA) no puede ser aplicado a Estados que han manifestado su consentimiento en obligarse por el mismo. ${ }^{33} \mathrm{El}$ segundo, la falta de obligatoriedad causó varias reflexiones relacionadas precisamente con este caso. Así, afirma Aguilar Cardoso: "la carencia de medidas coercitivas en el Sistema Interamericano, motivaron que el asunto fuera llevado al seno de las Naciones Unidas, cuya carta si establece dicho tipo de medidas en el caso de amenaza o alteración de la paz o seguridad internacionales". ${ }^{34}$ Al respecto, Perina explica:

En general, las decisiones de los cuerpos gobernantes de la Organización (e.g., Asamblea General, Reunión de Ministros de Relaciones Exteriores, Consejo Permanente) tienen el carácter de recomendaciones, sugerencias, o exhortaciones a los Estados miembros para cumplir con lo acordado en las Resoluciones. No son

33 Artículo 34 de la Convención de Viena sobre Derecho de los Tratados de 1969.

34 Aguilar Cardoso, Luis Enrique, La protección internacional de la democracia en el sistema interamericano: algunas propuestas de reforma de la Carta Democrática Interamericana, Comisión Andina de Juristas, http: / / www.cajpe.org.pe/mat_bol/Docs/CDI_Curso.doc. 
por lo tanto necesariamente vinculantes u obligatorias de cumplimiento. Así han sido, por ejemplo, las Resoluciones resultantes de las Reuniones ad hoc de Ministros de Relaciones Exteriores que han tratado las crisis de ruptura institucional democrática y la aplicación de la Resolución 1080. En todo caso, las Resoluciones sólo pueden solicitar o recomendar a los Estados miembros que apliquen sanciones e informen sobre las medidas adoptadas en el cumplimiento de lo decidido colectivamente ... La Organización tampoco tiene la competencia o la facultad, o la autonomía y capacidad coercitiva para ejecutar por sí sola las decisiones de los cuerpos gobernantes, o para forzar su aplicación para hacer cumplir las medidas acordadas. La Carta no permite el uso de la fuerza ni de medidas coercitivas. La Organización no es un ente supranacional independiente que puede actuar por si sola para hacer cumplir a los Estados miembros las decisiones de los cuerpos gobernantes. El caso de Haití es ilustrativo de este límite que enfrenta la Organización... [D]ada la incapacidad de hacer cumplir el embargo recomendado por decisión de la Reunión de Ministros, o de utilizar medidas coercitivas para desalojar al gobierno de facto y restaurar el legítimo del Presidente Aristide, se tuvo que recurrir (por parte del mismo Presidente Aristide con el apoyo de algunos Estados miembros de la OEA) al Consejo de Seguridad de la ONU, que sí impuso un embargo obligatorio contra el régimen de facto, y eventualmente permitió el uso de las medidas que se considerasen necesarias por sus miembros, incluso el uso de la fuerza, para asegurar el retorno del presidente Aristide. Esta opción de recurrir al organismo universal quedará siempre disponible si las decisiones de los cuerpos gobernantes, con sus límites, no son suficientes para conseguir los efectos deseados, y más aún si la situación en el país afectado por la interrupción de los procesos democráticos se convierte en clara e inminente amenaza a la seguridad y paz regional. ${ }^{35}$

En definitiva, y por las razones apuntadas, la resolución 841 (1993) del Consejo de Seguridad no debe ser entendida en el marco del artículo 53 de la Carta, sino como una forma de superar las limitaciones de

35 Perina, Rubén M., El régimen democrático interamericano: el papel de la OEA. http: / / www. cajpe.org.pe/mat_bol/Docs/6_perina.pdf. Véase, en el mismo sentido, Marchand Stens, Luis, "Reflexiones preliminares sobre la problemática derivada de la marginación del Tratado Interamericano de Asistencia Recíproca (TIAR), la viabilidad de un nuevo instrumento para la preservación de la paz en el ámbito hemisférico y el proceso en torno al nuevo concepto de la seguridad”, Comité Jurídico Interamericano, Informe Anual del Comité Jurídico Interamericano a la Asamblea General 2000, Documento OEA/Ser.Q/VI.31, OEA, Río de Janeiro, 2000, p. 36. 
la OEA, pues las medidas que ésta puede tomar sólo tienen vigencia en su ámbito regional y carecen de fuerza vinculante, y la única manera de adoptar medidas universales y obligatorias es que sean decididas por el Consejo de Seguridad.

Sin embargo, nada obsta a que, por vía convencional, se conceda a la OEA la facultad de adoptar medidas obligatorias, siempre y cuando las mismas no impliquen el uso de la fuerza armada (salvo los casos de legítima defensa). Al respecto, es interesante lo establecido en el artículo 20 del TIAR: "Las decisiones que exijan la aplicación de las medidas mencionadas en el Articulo 8o. serán obligatorias para todos los Estados signatarios del presente Tratado que lo hayan ratificado, con la sola excepción de que ningún Estado estará obligado a emplear la fuerza armada sin su consentimiento". Es decir, si el Órgano de Consulta decide exigir la aplicación de medidas, las mismas serán obligatorias, aunque, en el caso sub examine, de los términos de las resoluciones citadas no parece que haya sido esa su intención.

3. Algunos aspectos de las medidas coercitivas surgidos de la práctica del Consejo de Seguridad

De la acción tomada por el Consejo de Seguridad y los debates citados podemos extraer algunos aspectos de las medidas coercitivas del artículo 53:

- Indefinición en la Carta: la Carta no define qué ha de entenderse por “medidas coercitivas". Sin embargo, se destacó que el artículo 45 se refería expresamente al uso de la fuerza, y relacionaba directamente la "acción coercitiva internacional" con el empleo de las fuerzas armadas.

- Naturaleza coercitiva: se expresó que las medidas coercitivas son medidas colectivas tomadas por los Estados con objeto de obligar a otro Estado a seguir contra su voluntad una línea de conducta determinada, sin recurrir a la fuerza armada. En español, la palabra "coercitiva” designa a lo que sirve para forzar la voluntad o 
la conducta de alguien, ${ }^{36}$ en este caso, un Estado. En los debates se dijo que la expresión inglesa enforcement action era mucho más fuerte, pues implicaba el empleo de la fuerza o la violencia. Otro tanto sucedía con el texto francés, en que la expresión mesures coercitives procedía del verbo contraindre, que significaba "empleo de la violencia”.

- Implican el uso de la fuerza: hubo unanimidad en que comprendían aquellas acciones que preveían el empleo de la fuerza de manera que normalmente sería ilegítima para cualquier Estado o grupo de Estados (exceptuados los supuestos de legítima defensa y de acciones decididas por el Consejo de Seguridad), pero no existió consenso en cuanto a las medidas que no implican la fuerza, como las del artículo 41 de la Carta o del artículo 8o. del TIAR, aunque de la acción tomada por el Consejo puede deducirse que no se consideraron comprendidas.

- Solicitud de autorización por el organismo regional: en ninguno de los casos planteados, ni los órganos ni los miembros de la OEA recabaron la autorización del Consejo de Seguridad para adoptar medidas en relación con sus decisiones. El Órgano de Consulta y los miembros consideraron que sólo era preciso notificar tales medidas al Consejo de Seguridad con arreglo al artículo 54, que resulta aplicable a todas las medidas que no entrañen el uso de la fuerza. De haber considerado que eran medidas coercitivas, la organización o alguno de sus miembros habría solicitado la autorización, de conformidad al artículo 53.

- Necesidad de autorización del Consejo de Seguridad: el artículo 53 es claro al expresar que el Consejo debe "autorizar" las medidas coercitivas de los organismos regionales; sin embargo, en la resolución 156 (1960) (y — con las salvedades expuestas - en la Resolución 841 [1993]), se limitó a “tomar nota” de las medidas dispuestas por la OEA, lo cual no puede considerarse que implique una "autorización".

- Inaplicabilidad del artículo 53 cuando se trata de Estados miembros del organismo regional: se afirmó que no se requiere la autorización del Con-

36 Diccionario de la lengua española, Real Academia Española, 22a. ed., 2001, p. 392. 
sejo cuando las medidas van dirigidas a Estados miembros del organismo, en la medida que se hayan obligado a respetar sus decisiones de conformidad al instrumento constitutivo pertinente. ${ }^{37} \mathrm{La}$ situación es diferente; sin embargo, si las medidas analizadas se hubieran adoptado contra un Estado no miembro de la organización, en cuyo caso la prescripción del artículo 53 se actualiza, puesto que las resoluciones del organismo regional no generan obligaciones para los no miembros del mismo, requiriendo en todo caso la autorización del Consejo de Seguridad.

- Respeto de las facultades soberanas: se argumentó que las medidas relativas a la interrupción de relaciones diplomáticas y económicas eran actos políticos de la competencia de cualquier Estado soberano y, por consiguiente, de la competencia de los miembros de la OEA actuando colectivamente. No obstante, también se sostuvo que podía haber diferencias entre los derechos individuales de cada Estado y los derechos de los Estados en cuanto miembros de un organismo regional, ya que los derechos y las obligaciones de cada Estado podían fundirse con los derechos y las obligaciones de la organización regional en relación con la Carta; si bien un Estado tenía a título individual determinados derechos, algunos de éstos podían quedar subordinados como resultado de las obligaciones contraídas en virtud de otro tipo de relación establecida entre el organismo regional y la Carta, regida por las disposiciones del Capítulo VIII y, además, de la jerarquía de la Carta conforme al artícu -

37 Este aspecto nos parece dudoso, no obstante haberse planteado en los debates del Consejo, ya que el mismo sólo se puede aplicar a medidas que no implican el uso de la fuerza, como lo expresa Cardona Llorens: "si un Estado ha dado su consentimiento al tratado constitutivo de una organización internacional — de la que él, por tanto, es miembro- para que pueda adoptar medidas coercitivas que no impliquen el uso de la fuerza contra él en el caso de que viole determinadas normas fundamentales del ordenamiento jurídico internacional, nada ni nadie, ni siquiera el artículo 53 de la Carta, puede considerar que dicha práctica está prohibida por la Carta de las Naciones Unidas" (Cardona Llorens, Jorge, "Una relectura del artículo 53 de la Carta de las Naciones Unidas a la luz del proyecto de la CDI sobre responsabilidad internacional de los Estados”, en Drnas De Clément, Zlata (coord.), Estudios de derecho internacional público-En homenaje al profesor Ernesto J. Rey Caro, Córdoba, Drnas-Lerner Editores, 2002, p. 539. Pero si aceptamos que las medidas coercitivas implican el uso de la fuerza armada, la autorización del Consejo siempre será necesaria, aun cuando se apliquen contra miembros del organismo regional. 
lo 103. Sin embargo, no parece que los Estados miembros hayan renunciado implícitamente a facultades soberanas, máxime si estas no implican el uso de la fuerza. ${ }^{38}$ Por otra parte, el hecho de ser miembros de un organismo regional no puede restringir sus derechos más que lo expresamente dispuesto en su instrumento constitutivo, toda vez que el mismo artículo 52 de la Carta dispone que ninguna disposición se opone a la existencia de tales organismos "cuyo fin sea entender en los asuntos relativos al mantenimiento de la paz y la seguridad internacionales y susceptibles de acción regional”, poniendo como límite que los mismos y sus actividades "sean compatibles con los Propósitos y Principios de las Naciones Unidas".

\section{CONSIDERACIONES FINALES}

Después de esta revista a las medidas adoptadas por la OEA, las discusiones en el Consejo de Seguridad y las opiniones doctrinarias, podemos llegar a las siguientes conclusiones:

1) Las "medidas coercitivas" a las que hace referencia el artículo 53 de la Carta de las Naciones Unidas, y para cuya aplicación los organismos regionales requieren la autorización del Consejo de Se-

38 Como lo destaca Cardona Llorens en su nueva opinión citada supra, la evolución actual del derecho internacional en cuanto a la responsabilidad de los Estados por hechos internacionalmente ilícitos permite la aplicación de ciertas medidas colectivas. Dice al respecto el artículo 54 del "Proyecto de artículos sobre responsabilidad del Estado por hechos internacionalmente ilícitos", aprobado por la Comisión de Derecho Internacional: "Este capítulo [contramedidas] no prejuzga el derecho de cualquier Estado, facultado por el párrafo 1 del artículo 48 para invocar la responsabilidad de otro Estado, a tomar medidas lícitas contra ese Estado para asegurar la cesación de la violación y la reparación en interés del Estado lesionado o de los beneficiarios de la obligación violada". Aunque en su comentario la Comisión se esfuerza en distinguir entre estas clases de medidas y las adoptadas por organizaciones internacionales, a renglón seguido cita medidas dispuestas por algunas organizaciones. En definitiva, no se puede impedir a los Estados actuando colectivamente lo que se les permite al actuar a título individual, siempre y cuando las medidas que se dispongan no violen normas imperativas de derecho internacional, en particular, la abstención de la amenaza o el uso de la fuerza. 
guridad, se limitan a aquellas medidas que implican el uso de la fuerza armada. Ello es así por cuanto:

- De los términos del artículo 45 en el Capítulo VII de la Carta de las Naciones Unidas surge que las "medidas coercitivas" son las que implican el uso de la fuerza armada, y en aras de una interpretación sistemática y armónica de la Carta no es posible sostener que en el Capítulo VIII tengan otro alcance.

- La OEA adoptó medidas que no implican el uso de la fuerza armada en varias oportunidades, a través de la Reunión de Consulta de Ministros de Relaciones Exteriores, o de una Reunión ad hoc, y no requirió (ni tampoco sus Estados miembros) en ningún caso la autorización o aprobación del Consejo de Seguridad, limitándose a notificarlo de conformidad al artículo 54 de la Carta.

- De la práctica del Consejo de Seguridad no surge que haya sido necesario requerir su autorización para que los organismos regionales apliquen medidas que no implican el uso de la fuerza. En efecto, en la resolución 156 (1960) se limitó a "tomar nota” de las medidas adoptadas por la OEA. La resolución 841 (1993), por plantear un supuesto diferente, no modifica esta interpretación.

- Los Estados pueden, en determinadas condiciones y sujetos a ciertos límites, aplicar contramedidas legítimas, y nada impide que lo que pueden hacer a título individual, también puedan hacerlo actuando colectivamente.

2) La OEA está autorizada a tomar medidas que no implican el uso de la fuerza armada, en virtud de su Carta y el TIAR, sujetas a los presupuestos y alcance previstos en esas normas. Tales medidas, adoptadas por los órganos competentes, sólo serán obligatorias para los miembros si se les asigna expresamente ese carácter (artículo 20 del TIAR).

3) Para que la OEA pueda aplicar medidas coercitivas (es decir, que impliquen el uso de la fuerza), que no sean en ejercicio del derecho de legítima defensa colectiva (de conformidad con el artículo 51 de la Carta de las Naciones Unidas y elTIAR), debe requerir la autorización del Consejo de Seguridad, en virtud del artículo 53 de la Carta de las Naciones Unidas. 
4) De la misma manera, para que las medidas que está autorizada a tomar la OEA tengan validez y obligatoriedad universal (esto es, que se apliquen a Estados que no son miembros de la organización), deben ser adoptadas por el Consejo de Seguridad.

\section{BIBLIOGRAFÍA}

Aguilar Cardoso, Luis Enrique, La protección internacional de la democracia en el Sistema Interamericano: algunas propuestas de reforma de la Carta Democrática Interamericana, Comisión Andina de Juristas, http:// www.cajpe.org.pe/mat_bol/Docs/CDI_Curso.doc.

AliCE, Mauricio, El sistema jurídico interamericano, Buenos Aires, ISEN, 2006.

Barboza, Julio, Derecho internacional público, Buenos Aires, Zavalía, 1999.

Berenson, William M., La estructura de la Organización de los Estados Americanos: una reseña, http: / / www.oas.org/legal/spanish/WMB\%20CA RTA\%20DE\%LA\%20OEA\%20REV\%2029\%20de\%20enero\%20de\%20 2002.doc.

CARdona Llorens, Jorge, "El mantenimiento de la paz y la seguridad internacionales", en Diez de Velasco Vallejo, Manuel, Las Organizaciones Internacionales, 10a. ed., Madrid, Tecnos, 1997.

, "El mantenimiento de la paz y la seguridad internacionales", en Diez de Velasco Vallejo, Manuel, Las Organizaciones Internacionales 13a. ed., Madrid, Tecnos, 2003.

, "Una relectura del artículo 53 de la Carta de las Naciones Unidas a la luz del proyecto de la CDI sobre responsabilidad internacional de los Estados”, en DrNas De ClÉment, Zlata (coord.), Estudios de derecho internacional público-En homenaje al profesor Ernesto J. Rey Caro, Córdoba, Drnas - Lerner Editores, 2002.

CIJ, Certaines dépenses des Nations Unies (article 17, paragraphe 2, de la Charte), Avis consultatif du 20 juillet 1962. C. I.J . Recueil 1962.

Consejo de Seguridad. Acta oficial de la 1022a. sesión. Documento S/ PV.1022. Nueva York, Naciones Unidas, 1962. 
Consejo de Seguridad. Acta oficial de la 1024a. sesión. Documento S/ PV.1024. Nueva York, Naciones Unidas, 1962.

COnSEJO DE SEguridAd, Acta taquigráfica provisional de la 3238a. sesión. Documento S/PV.3238. Nueva York, Naciones Unidas, 1993

DE VOldER, Eefje, Regionalism under the United Nations Framework. Exploring the limits and possibilities for regional enforcement action under the UN Charter with a special focus on Chapter VIII UN Charter. http: / / arno.uvt. nl/show.cgi?fid =114833.

DelPeCH, Marcelo, Carta de las Naciones Unidas anotada, Buenos Aires, Zavalía, 2005.

HAKIMI, Monica, "To condone or condemn? Regional enforcement actions in the absence of Security Council authorization”, Vanderbilt Journal of Transnational Law, Vanderbilt University, School of Law, 2007.

Kodjon, Edem, “Article 53”, en Cot, Jean-Pierre y Pellet, Alain, La Charte des Nations Unies. Commentaire article par article, 2a. ed., París, Economica, 1985.

MARCHAND STENS, Luis, "Reflexiones preliminares sobre la problemática derivada de la marginación del Tratado Interamericano de Asistencia Recíproca (TIAR), la viabilidad de un nuevo instrumento para la preservación de la paz en el ámbito hemisférico y el proceso en torno al nuevo concepto de la seguridad", Comité Jurídico Interamericano, Informe Anual del Comité Jurídico Interamericano a la Asamblea General 2000, Documento OEA/Ser.Q/VI.31. OEA. Río de Janeiro, 2000.

Naciones Unidas, Carta del 3 de octubre de 1991 dirigida al secretario general por el representante permanente de Honduras ante las $\mathrm{Na}$ ciones Unidas, Apéndice. Documento A/46/231. Nueva York, 1991.

Naciones Unidas, Carta de fecha 7 de junio de 1993 dirigida al presidente del Consejo de Seguridad por el representante permanente de Haití ante las Naciones Unidas. Documento S/25958. Nueva York, 1993.

Naciones Unidas, Carta del 9 de octubre de 1991 dirigida al secretario general por el representante permanente de Honduras ante las $\mathrm{Na}$ ciones Unidas, Apéndice. Documento A/46/550 - S/23127. Nueva York, 1991. 
Naciones Unidas, Carta del 23 de octubre de 1962 dirigida al secretario general interino de las Naciones Unidas por el secretario general de la Organización de los Estados Americano. Documento S/5193. Nueva York, 1962.

Naciones Unidas, Informe de la Comisión de Derecho Internacional sobre la labor en su $53^{\circ}$ período de sesiones. Documento A/56/10. Nueva York, 2001.

Naciones Unidas, Repertorio de la práctica seguida por los Órganos de las Naciones Unidas - Suplemento N³. Nueva York, 1971, vol. II, artículo 53.

OEA, "Acta Final de la Décima Reunión de Consulta de Ministros de Relaciones Exteriores”, Washington DC, 1o. de mayo de 1965-6 de marzo de 1970.

OEA, "Acta Final de la Octava Reunión de Consulta de Ministros de Relaciones Exteriores”. Punta del Este, Uruguay, 22 a 31 de enero de 1962.

OEA, "Acta Final de la Sexta Reunión de Consulta de Ministros de Relaciones Exteriores”, San José, Costa Rica, 16-21 de agosto de 1960.

PERINA, Rubén M., El régimen democrático interamericano: el papel de la OEA, http: / /www.cajpe.org.pe/mat_bol/Docs/6_perina.pdf.

VARGAS CARREÑO, Edmundo, "El principio de no intervención y su vigencia en el derecho internacional del siglo XXI", en MÉNDEZ SILVA, Ricardo (coord.), Derecho y seguridad internacional. Memoria del Congreso Internacional de Culturas y Sistemas Jurídicos Comparados, México, UNAM, 2005.

VILlani, Ugo, “The Security Council's Authorization of Enforcement Action by Regional Organizations", en Frowein, L. A. y Wolfrum, R. (eds.), Max Planck Yearbook of United Nations Law, Kluwer Law International, 2002, vol. 6. 